\title{
Experimental study and analytical analysis on the global heat transfer of stratified corium in LWR lower head
}

\author{
X. Gaus-Liu ${ }^{1}$ Th. Cron ${ }^{1}$ and B. Fluhrer ${ }^{1}$, Th. Wenz ${ }^{1}$ \\ ${ }^{1}$ Karlsruhe Institute for Technology, Eggenstein-Leopoldshafen, Germany \\ Xiaoyang.gaus-liu@kit.edu, Thomas.cron@kit.edu, Beatrix.fluhrer@kit.edu, Thomas.wenz@kit.edu
}

\begin{abstract}
In-Vessel Melt Retention (IVR) is credited as a promising Severe Accident Management strategy to stabilize the molten corium during severe accident scenarios. This strategy is not only adopted in VVER 440 or AP600 designs, but is also included in higher power reactors around $1000 \mathrm{MWe}$, such as AP1000 and Chinese CPR 1000. One of the current research priorities bound with large uncertainty is the heat flux at the cooled wall in the metallic layer atop of a ceramic pool, as heat flux focusing effect could appear at this location. The generation of experimental data with naturally separated melt layers is essential to improve the understanding of the heat transfer between the melt layers and on their boundaries. Under the framework of EU H2020 IVMR project, two large-scale test series with simulant materials were conducted in LIVE2D facility at KIT. Rigid top cooling and hot atmosphere on the upper layer were realized in a two-layer melt pool with different upper layer thicknesses. Important global heat transfer phenomena have been obtained, including the effect of the top cooling boundary, the behaviour of the interlayer crust and the impact of upper layer thickness. Finally, the influence of Pr number and geometry are discussed.
\end{abstract}

Key Words:

In-Vessel melt retention, stratified corium, LIVE2D, heat flux focusing effect, interlayer crust

\section{Introduction}

IVR strategy is implemented in the severe accident management strategy for several light-water reactor designs, which will be activated when the core inventory is relocated in the lower head of the reactor pressure vessel (RPV). In the case that water injection into the RPV does not work due to loss of coolant or the high pressure inside the vessel, the decay heat inside the corium in the lower head can alternatively be transferred through the vessel wall via flooding the RPV externally. The success of the external cooling relies on that the heat flux through the vessel should not exceed the cooling ability of the waterside [1]. Analyses of Theofanous and Esmaili have shown that IVR with external cooling can be successful for AP600 and AP1000-like designs for a homogenous ceramic melt pool [2] [3]. This strategy is even examined for higher power reactors e.g. APR1400 [4]. However, the uncertainty exists on the heat flux at the vessel wall of a light metallic layer atop of the ceramic layer, e.g. up to $30 \%$ for AP1000 design.

The corium stratification and the existence of a light metallic layer is very likely to occur in different accident scenarios. Its existence is experimentally demonstrated in MASCA Program [5] and followup programs, although its origin and the time being of occurrence can be quite different according to accident procedures, and they remain as matters of discussion [6]. The light metallic layer is composed majorly of molten steel from the construction inventory and vessel wall, can contain minor 
concentration of $\mathrm{Zr}$ and $\mathrm{U}$. There is also an uncertainty in the heat source density in the metallic layer, which depends on the migration of metallic Uranium into this layer [7]. For a thin metallic layer heated from the underlying ceramic pool and with limited cooling at the upper surface, the heat flux focusing effect at the sidewall is likely to occur. There is high awareness of the heat flux focusing effect in the light metallic layer in all reactor designs, whereas the designs with possibly large iron mass at the beginning take the advantage to suppress the heat flux focusing effect by increasing the sidewall area $[8,9]$.

In the European IVMR project a new PIRT (Phenomena Identification and Ranking Table) regarding in-vessel severe accident phenomena has been developed applying innovative risk evaluation methodology and including mechanical load assessments [10]. The new PIRT reassesses the uncertainties of the characteristics of top metallic layer, and shows that the upper layer characteristics possess the highest overall impact factor of uncertainties. Most uncertainties related to or affecting the upper metallic layer characteristics are in the high-ranking uncertainty list, e.g. kinetics of stratification, correlations of heat transfer in upper metallic layer, chemical interactions between metal and oxide crust, molten pool formation, transient establishment of heat transfer, and the crust mechanical resistance.

Parallel to the examination of the physical-chemical interactions of prototypical materials in small volumes, large-scale melt stratification experiments with high Ra number are urgently needed to provide global heat transfer characteristics of a stratified melt pool. The challenge of the large largescale experiments is mainly the search of a combination of simulants, which should fulfil the character of the two-layer configuration with an oxide lower layer and a light metallic layer. Ideally, the two simulants are separated naturally from each other; the lower layer has the character of an oxide melt and can form crust, and the upper layer represents the thermal-hydraulic character of liquid metal. These high requirements are so demanding that they could not be completely fulfilled in the previous experiments. BALI tests had only the upper layer test section and used water as the upper layer simulant [11]. The 3D SIMECO tests applied Glycerol/Cerrobend and Nitrate salt/Cerrobend as upper layer/lower layer material combinations. The Nitrate salt can form crust at the boundaries. The upper layer simulant Cerrobend represents more the character of oxide than the one of a liquid metal. Interesting results have been obtained with the Ra numbers in the range of $10^{4}-10^{5}$ [12]. However, extrapolation of the SIMECO results to the reactor case with Ra numbers in the range of $10^{9}-10^{10}$ is quite uncertain. KIT has performed a two-layer test in LIVE3D facility using nitrate salt for the both layers, which were separated by a copper plate [13]. Moon \& Chung examined the heat transfer at the upper horizontal surfaces in a one-layer test section using $\mathrm{H}_{2} \mathrm{SO}_{4}-\mathrm{CuSO}_{4}$ as simulants and the heat flux was measured with limiting current technology. The sidewall heat flux was not the subject of investigation [14].

A new attempt of large-scale melt stratification tests was undertaken in the upgraded LIVE2D test facility as a task within the IVMR project [15]. Thermal oil and nitrate salt were selected as upper layer and lower layer simulants respectively. The density difference of the two simulants guarantees the separation of the two simulants. The crust formation of the nitrate salt behaves similar as the oxide melt. The purpose of the investigation is the global behaviour of the thermal interaction between the layers including the interlayer crust behaviour at different upper layer thicknesses and upper surface cooling conditions. The upper layer $\mathrm{Ra}$ is $\sim 10^{9}$, thus in the same scale as in the reactor case. Since the thermal oil has a higher Pr than liquid metal, the effect of the non-similarity of the material properties and the 2D geometry effects are discussed at the end. 


\section{Experimental performance}

\subsection{Test facility}

The LIVE2D test vessel in semicircular slice geometry simulates the RPV lower head (Figure 1) in 1:5 linear scale [16]. The vessel inner diameter is $1 \mathrm{~m}$, and the width is $12 \mathrm{~cm}$. The vessel material is stainless steel and the wall thickness is approx. $24 \mathrm{~mm}$. The vertical backside of the test vessel is insulated and the complete front side is equipped with two quartz plates, which enable direct visualization of the melt pool. The curved vessel wall, simulating the reactor vessel wall, is enclosed in a water cooling channel. Two boundary conditions can be realized on the melt upper surface: a hot boundary and a rigid cooled boundary. The hot boundary is created by covering the vessel upper edge with a metallic plate, leaving a hot air atmosphere above the melt surface; whereas the rigid cooling boundary means that a water-cooled steel lid is placed directly on the melt surface. The decay heat is simulated with nine planes of independently controlled electrical resistance heating wires. LIVE2D shares the melt preparation system and infrastructure with the LIVE3D facility [13].

The liquid oxide melt can be prepared in an external heating furnace and be poured into the test vessel via a preheated pouring spout. At the end of a test, the liquid melt can be extracted back to the heating furnace.

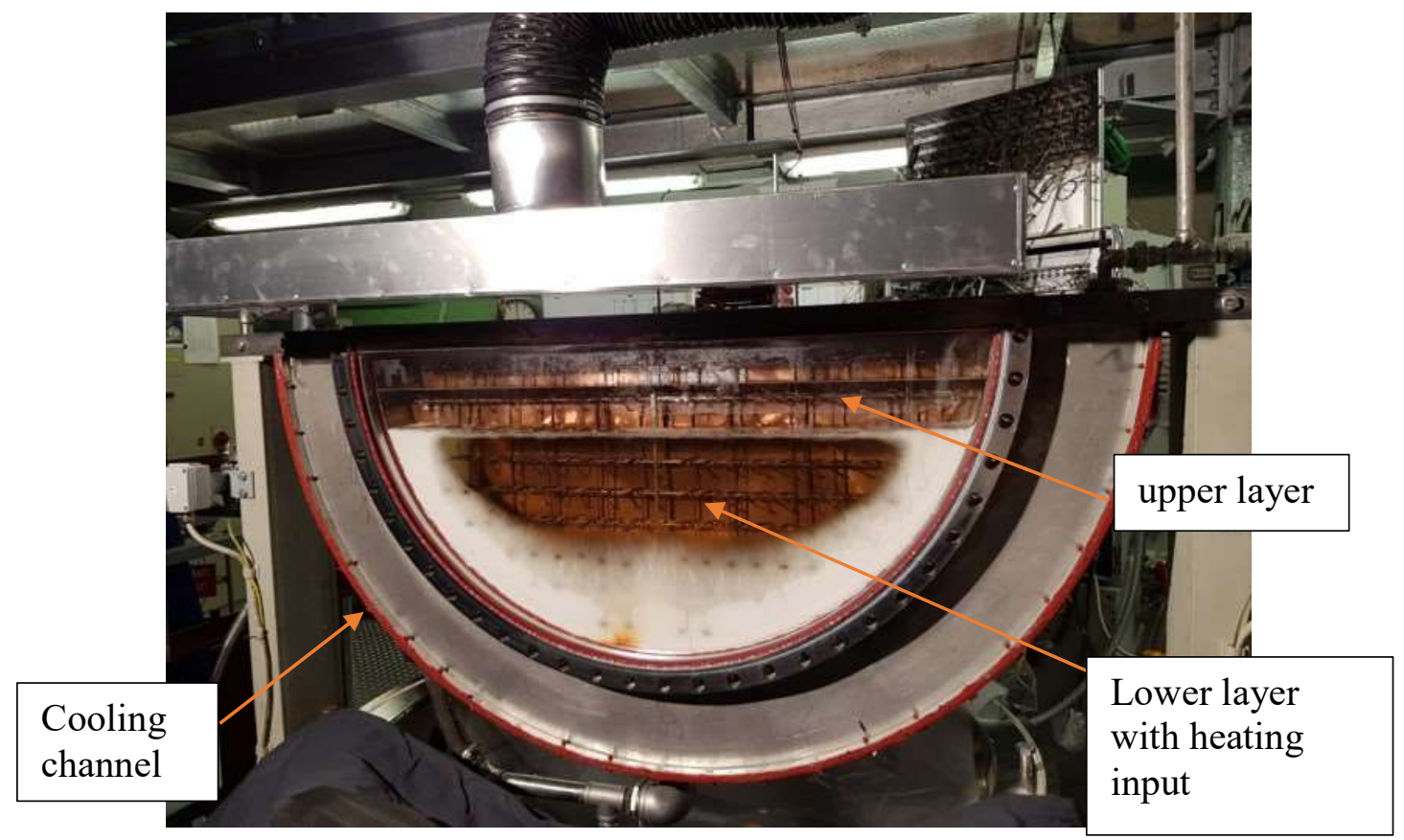

Figure 1. LIVE2D test facility with a hot upper boundary in SO1 test.

The major instrumentation inside and on the test vessel wall is temperature measurement with K-Type thermocouples (TCs), as shown in Figure 2. This includes the bulk melt temperature (MT), vessel wall inner surface temperature (IT), outer surface temperature (OT), boundary layer temperature at the vessel wall (CT trees), where five TCs are arranged linearly in $5 \mathrm{~mm}$ distance between each other. "HE*a" TCs measure the surface temperature of heaters, and serve as control temperature if the controlled heater is in operation, otherwise they measure the local melt temperature. The determination of heat flux is based on the IT and OT thermocouples, wall thickness and the thermal conductivity of the vessel wall. In Table 2 the positions of the IT/OTs and the positions of the upper layer upper boundaries are given. Besides the fixed thermocouples in the vessel, three mobile 
temperature lances (LT) are installed at the vessel top, which measure the temperature in the whole upper layer in three radii of $4 \mathrm{~mm}, 290 \mathrm{~mm}$ and $390 \mathrm{~mm}$ in SO1 test. In SOTC test, three thermocouple trees are mounted on the cooling lid (DCT), as shown in Figure 2, providing additional values of the vertical and radial temperature distribution in the upper layer.

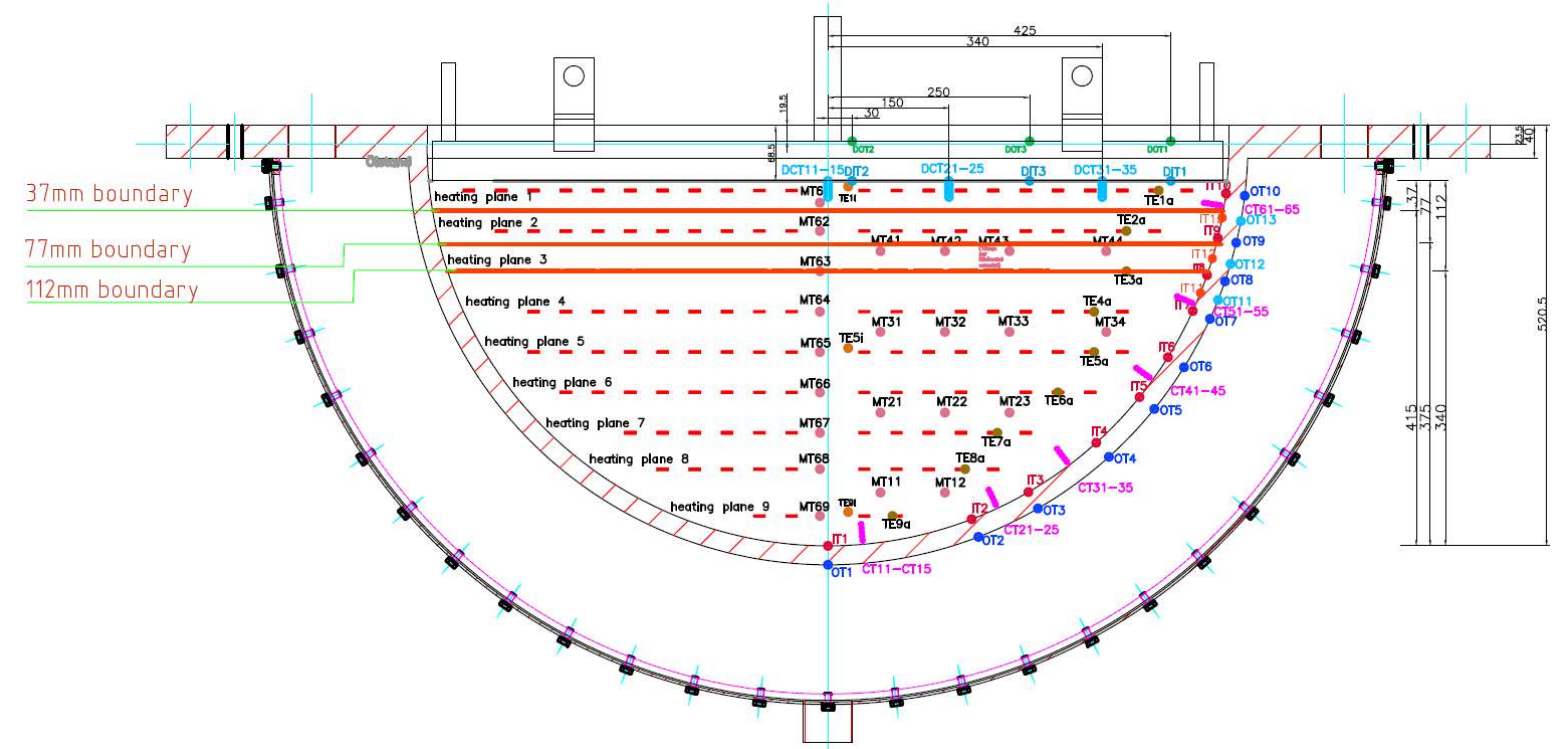

Figure 2. Instrumentation scheme of SOTC test.

Table 1.

Thermocouple (TC) positions at wall inner surface (IT) and the upper layer positions, and the positions of layer interface.

\begin{tabular}{|c|c|c|c|c|c|c|c|c|}
\hline \multicolumn{3}{|c|}{ Lower layer } & \multicolumn{3}{|c|}{ Upper layer } & \multicolumn{3}{|c|}{ Interface/upper surface position } \\
\hline TC & $\begin{array}{c}\text { Polar } \\
\text { angle, }^{\circ}\end{array}$ & $\begin{array}{c}\text { Height, } \\
\mathrm{mm}\end{array}$ & TC & $\begin{array}{c}\text { Polar } \\
\text { angle, } \\
\text { on }\end{array}$ & $\begin{array}{l}\text { Height, } \\
\mathrm{mm}\end{array}$ & S01 test & $\begin{array}{c}\text { Polar } \\
\text { angle, }^{\circ}\end{array}$ & $\begin{array}{c}\text { Height, } \\
\mathrm{mm}\end{array}$ \\
\hline IT1 & 0 & 0 & IT12 & 73 & 355 & Layer interface & 71.6 & 340 \\
\hline IT2 & 21 & 33 & IT9 & 76 & 376 & $35 \mathrm{~mm}$ upper layer & 75.8 & 375 \\
\hline IT3 & 30 & 67 & IT13 & 80 & 406 & $75 \mathrm{~mm}$ upper layer & 80.5 & 415 \\
\hline IT4 & 42 & 128 & IT10 & 83 & 436 & $110 \mathrm{~mm}$ upper layer & 84.6 & 450 \\
\hline IT5 & 51 & 184 & & & & SOTC test & $\begin{array}{c}\text { Polar } \\
\text { angle, }^{\circ}\end{array}$ & $\begin{array}{c}\text { Height, } \\
\mathrm{mm}\end{array}$ \\
\hline IT6 & 58 & 234 & & & & Layer interface $37 \mathrm{~mm}$ & 80.5 & 415 \\
\hline IT7 & 66 & 291 & & & & Layer interface $77 \mathrm{~mm}$ & 75.8 & 375 \\
\hline IT11 & 68 & 313 & & & & Layer interface $112 \mathrm{~mm}$ & 71.6 & 340 \\
\hline IT8 & 71 & 335 & & & & & & \\
\hline
\end{tabular}

For the optical observation of the motion of the melt and the supervision of the upper layer crust thickness, real-time video camera and time-lapse video camera were installed in front of the transparent sidewall. Heat transfer rate of the external cooling water was determined based on the flow rate and water inlet and outlet temperatures. 


\subsection{Simulant materials}

The eutectic nitrate salt mixture with the molar ratio of $50 \% \mathrm{KNO}_{3}-50 \% \mathrm{NaNO}_{3}$ and a thermal oil were selected as the lower layer and upper layer simulants respectively. The two materials are immiscible with each other and are not corrosive to vessel components. An interlayer crust can be formed or molten down naturally depending on the power level and heat transfer between the layers. In addition, there is a wide temperature range of their co-existence in liquid states. The thermalhydraulic properties of the lower layer simulant can well represent oxidic corium character; however, the upper layer material possesses a higher Pr number than the light metal layer does due to its high viscosity and low thermal conductivity. This material aspect will be discussed in a later section. The material properties are given in Table 2 and the properties of the nitrate mixtures are provided by [17].

Table 2.

Simulant material properties.

\begin{tabular}{|c|c|c|c|c|c|}
\hline \multirow[t]{2}{*}{ Properties } & \multicolumn{2}{|c|}{$\begin{array}{c}\text { Lower layer simulant: } \\
50 \% \mathrm{KNO}_{3}-50 \% \mathrm{NaNO}_{3}\end{array}$} & \multicolumn{2}{|c|}{$\begin{array}{c}\text { Upper layer simulant: } \\
\text { Thermal oil }\end{array}$} & Liquid steel \\
\hline & at $224^{\circ} \mathrm{C}$ & at $260^{\circ} \mathrm{C}$ & at $140^{\circ} \mathrm{C}$ & at $220^{\circ} \mathrm{C}$ & at $1327^{\circ} \mathrm{C}$ \\
\hline Density, $\mathrm{kg} / \mathrm{m}^{3}$ & 1964 & 1937 & 755 & 540 & 7020 \\
\hline Kinematic viscosity, $\mathrm{mm}^{2} / \mathrm{s}$ & 2.76 & 2.23 & 11 & 9 & $5.84 \mathrm{E}-7$ \\
\hline $\begin{array}{l}\text { Thermal expansion coefficient, } \\
(1 / \mathrm{K}) \times 10^{-4}\end{array}$ & \multicolumn{2}{|c|}{1.05} & \multicolumn{2}{|c|}{44} & 1.1 \\
\hline Thermal conductivity, $\mathrm{W} /(\mathrm{mK})$ & 0.48 & 0.47 & 0.15 & 0.15 & 25 \\
\hline Thermal capacity, J/(gK) & 1.29 & 1.31 & 1.7 & 1.83 & 0.835 \\
\hline $\operatorname{Pr}$ & 14.5 & 12.0 & 94 & 59 & 0.14 \\
\hline $\mathrm{Ra}$ sidewall & \multicolumn{2}{|c|}{$10^{12}-10^{13}$} & \multicolumn{2}{|c|}{$10^{8}-10^{9}$} & $10^{8}$ \\
\hline
\end{tabular}

\subsection{Test procedure}

In the LIVE2D-SO1 test series, a 2-layer melt configuration with hot upper atmosphere has been realized. Three upper layer thicknesses in the subsequence of $35 \mathrm{~mm}, 75 \mathrm{~mm}, 110 \mathrm{~mm}$ and $75 \mathrm{~mm}$ were realized for a total test duration of about 100 hours. The lower layer height was kept at $340 \mathrm{~mm}$ during the whole test. Only the lower layer was heated volumetrically, simulating the prototypical case of decay heat release in the lower oxide layer. The vessel wall was externally cooled with water and the upper surface of the vessel was covered with a thin metal plate, leaving a hot air atmosphere above the melt surface, and free slip boundary on the upper surface. In the SOTC test series, the total melt pool height was kept at $452 \mathrm{~mm}$, and the upper surface was bounded with the cooling lid bottom. The upper layer thickness was realized by changing the interlayer position, which are given in Table 3. In Table 3 the main features of the two test series are given. 
Table 3.

Test performance of SO1 and SOTC tests.

\begin{tabular}{|c|c|c|c|c|c|c|c|}
\hline \multirow[b]{2}{*}{ Test } & \multicolumn{2}{|c|}{ Simulant material } & \multicolumn{2}{|c|}{ Height of layer, mm } & Heating phase, $\mathrm{W}$ & \multicolumn{2}{|c|}{ Boundary condition } \\
\hline & $\begin{array}{l}\text { Upper } \\
\text { layer }\end{array}$ & $\begin{array}{l}\text { Lower } \\
\text { layer }\end{array}$ & $\begin{array}{l}\text { Upper } \\
\text { layer }\end{array}$ & $\begin{array}{l}\text { Lower } \\
\text { layer }\end{array}$ & $\begin{array}{l}\text { heating only in lower } \\
\text { layer }\end{array}$ & Top surface & Vessel wall \\
\hline \multirow{4}{*}{ SO1 } & \multirow{4}{*}{$\begin{array}{l}\text { Thermal } \\
\text { oil }\end{array}$} & \multirow{4}{*}{ Nitrate salt } & 35 & 340 & $\begin{array}{c}1300-940-1040- \\
1310-1400-900\end{array}$ & \multirow{4}{*}{ Hot air } & \multirow{4}{*}{$\begin{array}{l}\text { Water } \\
\text { cooled }\end{array}$} \\
\hline & & & 75 & 340 & $1300-1800-1150$ & & \\
\hline & & & 110 & 340 & $\begin{array}{c}2200-1800-1400- \\
1600\end{array}$ & & \\
\hline & & & 75 & 340 & 1600 & & \\
\hline \multirow{3}{*}{ SOTC } & \multirow{3}{*}{$\begin{array}{l}\text { Thermal } \\
\text { oil }\end{array}$} & \multirow{3}{*}{ Nitrate salt } & 112 & 340 & $3000-3600-4250$ & \multirow{3}{*}{$\begin{array}{l}\text { Water } \\
\text { cooled }\end{array}$} & \multirow{3}{*}{$\begin{array}{l}\text { Water } \\
\text { cooled }\end{array}$} \\
\hline & & & 77 & 375 & $4230-3000-3600$ & & \\
\hline & & & 37 & 415 & $\begin{array}{c}3600-3000-4300 \\
-3400-2400-1800\end{array}$ & & \\
\hline
\end{tabular}

\section{Experimental Results}

\subsection{Interlayer Crust}

The interlayer crust melts down or builds up depending on the interlayer temperature, which is a process parameter of heat transfer within and between the two layers. Figure 3 shows the two-layer interface during the two test series. During a test phase with low heating power in the lower layer, a crust layer built up at the interface, whereas this crust layer was molten down when the power in the lower layer increased. In the case of SO1 test, where the upper surface cooling was limited, the interlayer crust was always thinner at the radial centre than at the cold region near the wall, and the crust thickness was not uniform in radial direction. The crust behaviour was different in the SOTC test with rigidly cooled upper surface. The interlayer crust thickness was almost uniform from the axial centre to the sidewall. The change of the crust layer thickness was almost synchronic along the whole crust layer, except at the outermost edge to the wall. For both tests, the crust stabilization (growth or meltdown) transient was longer than the temperature stabilization transient in the lower layer, which led to a correspondingly longer transient period in the upper layer.

It is also worth noting that an interlayer crust existed during high power in the lower layer during SOTC test, whereas it was already molten down in SO1 test at the same power. It demonstrates that the surface cooling in SOTC test was very effective to keep the temperature in the upper layer low and enabled the existence of the interlayer crust. The status of the interlayer crust during both tests is summarized in Table 4. 


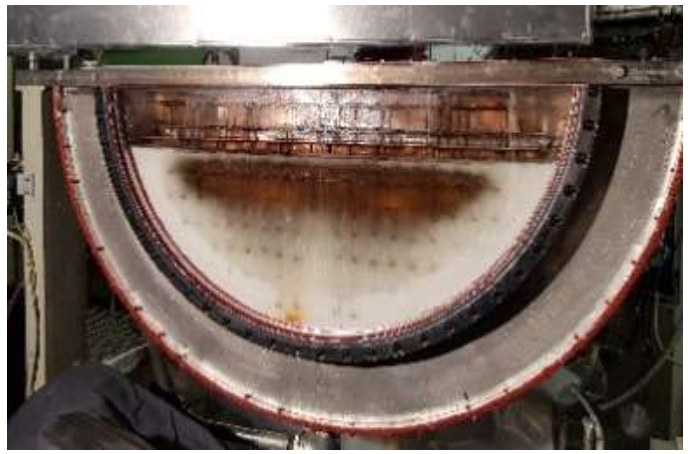

(a) SO1, $0.9 \mathrm{~kW}, 35 \mathrm{~mm}$ upper layer

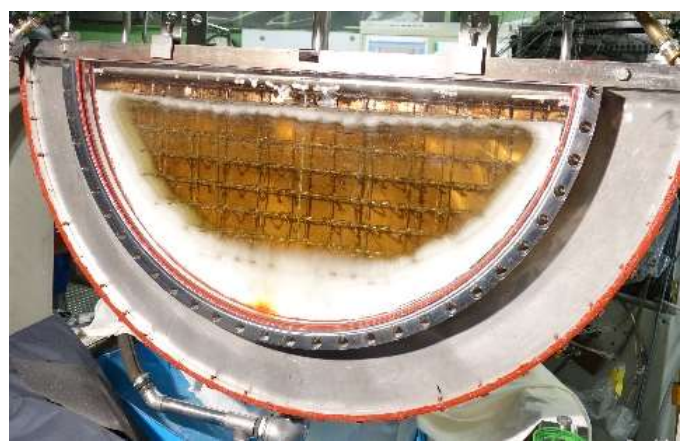

(c) SOTC, $1.8 \mathrm{~kW}, 37 \mathrm{~mm}$ upper layer

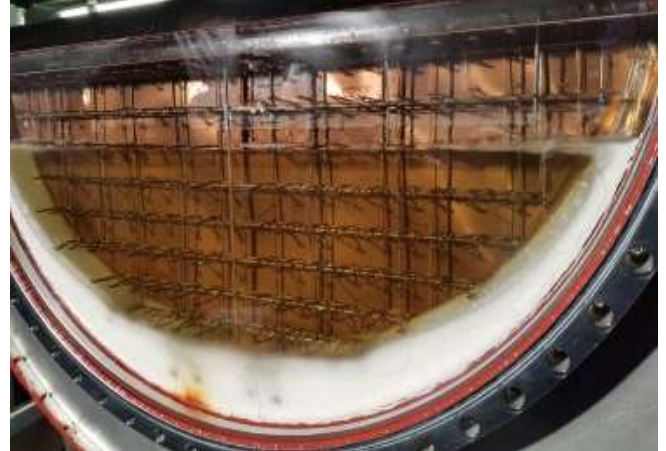

(b) SO1, $1.8 \mathrm{~kW}, 110 \mathrm{~mm}$ upper layer

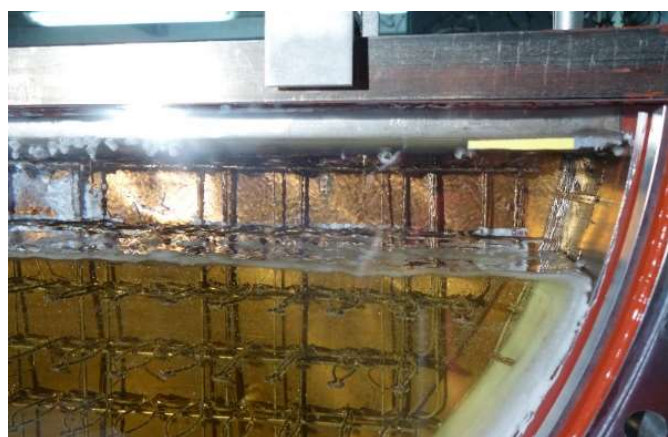

(d) SOTC, $3.6 \mathrm{~kW}, 75 \mathrm{~mm}$ upper layer

Figure 3. (a) closed interlayer crust in SO1 test at $0.9 \mathrm{~kW}$, (b) broken interlayer crust in SO1 test at $1.8 \mathrm{~kW}$, (c) closed thin crust in SOTC test with $1.8 \mathrm{~kW}$; (d) broken crust layer in SOTC test with 3.6 $\mathrm{kW}$.

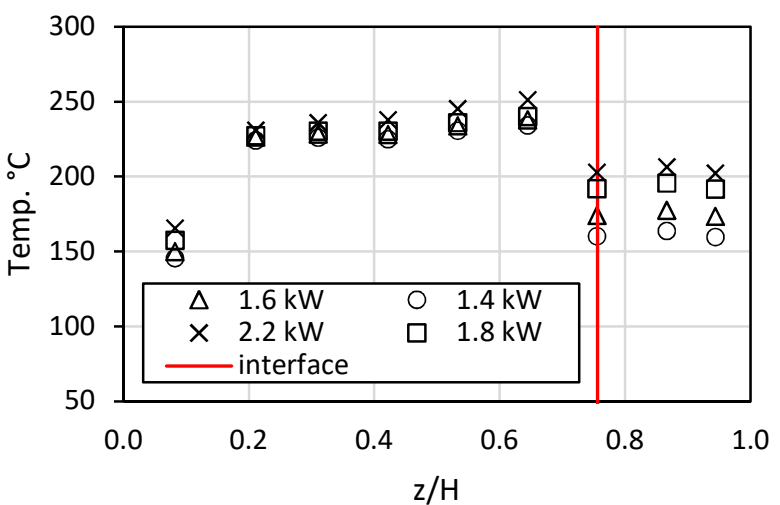

(a) SO1 with $110 \mathrm{~mm}$ upper layer

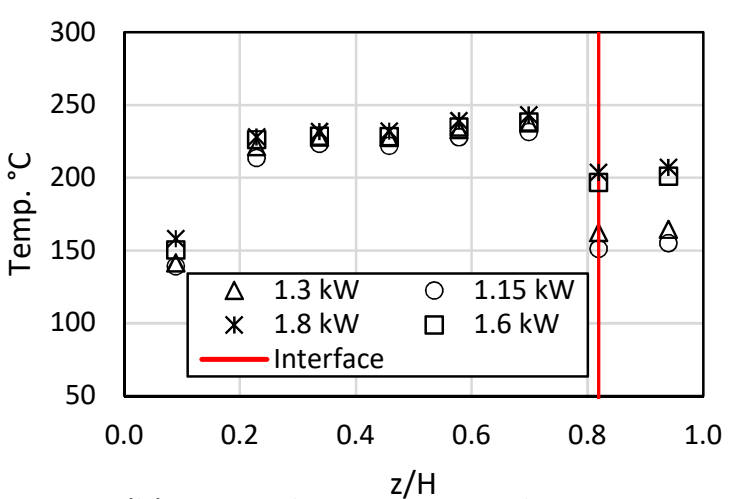

(b) SO1 with $75 \mathrm{~mm}$ upper layer 


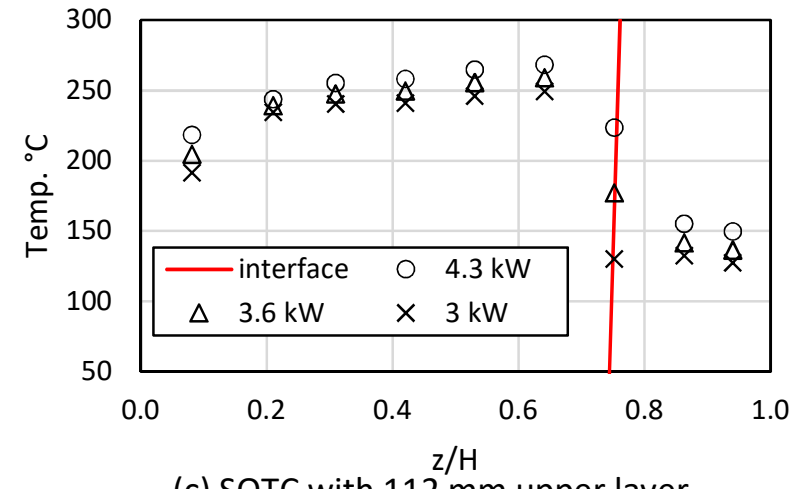

(c) SOTC with $112 \mathrm{~mm}$ upper layer

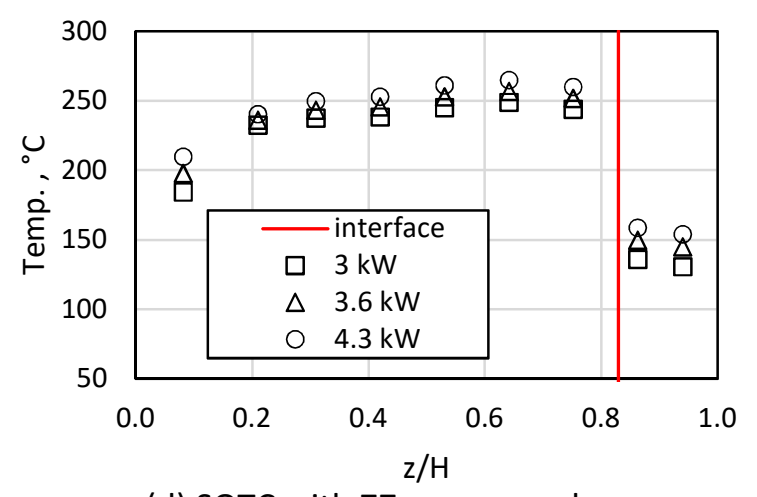

(d) SOTC with $77 \mathrm{~mm}$ upper layer

Figure 4. Melt temperature vertical distribution at radius of $30 \mathrm{~mm}$ during the steady state of SO1 and SOTC tests.

\subsection{Melt temperature}

Melt temperature in a closed cavity is a variable parameter, which adjusts itself automatically to the interaction of the heat source and the heat transfer on the boundaries. As long as an interlayer crust exists, the upper boundary temperature of the lower layer is its liquidus temperature, and thus the upward heat transfer in the lower layer is independent on the melt temperature of the upper layer. The heat transfer rate from the lower layer through the interface crust can be therefore estimated based on the temperature difference between the bulk and the liquidus temperature.

The interlayer heat transfer becomes more complicated when the crust layer is partially or completely molten. At the interface position where no crust exists, the heat transfer is coupled with the liquidliquid interface temperature, which is a variable parameter and higher than the liquidus temperature of the lower layer melt. The elevated interface temperature has a throttling effect on the interlayer heat transfer due to the reduced temperature difference in the lower layer. Simultaneously, the sidewall heat flux in the lower layer increases to compensate the reduced upward heat transfer ratio. This leads to redistribution of up/down heat splitting in the lower layer and a reduction of the heat flux focusing effect in the upper layer. Figure 4 shows the vertical melt temperature distribution of the two layers at axial centre position. The slight change of the interlayer position in Figure 4 (c) came from the lower layer volume change due to the thermal expansion rates at different powers. The power input SO1 test was limited, since the upper layer temperature increased sensitively at higher power and the operational upper layer temperature is limited up to $220^{\circ} \mathrm{C}$.

Increasing the upper layer thickness can effectively depress the melt temperature in SO1 test. In comparison, higher power was tolerable in SOTC test, and upper layer temperature remained low and was less sensitive either to the lower layer power or to the layer thickness. During the SOTC $110 \mathrm{~mm}$, $4.3 \mathrm{~kW}$, the layer interface was crust-free.

The upper layer temperature distribution at different radial positions is shown in Figure 5. The height positions and radial positions are scaled dimensionless in reference to the upper layer height, $H_{u p}$ and vessel radius $R$.

In SO1 test the upper layer melt was characterized by apparently large boundary layers at the bottom and at the upper surface and uniform bulk temperature in the middle height, as shown in Figure 5 (a) and (b). Without an interlayer crust, as the case in Figure 5 (a), the interlayer temperature was 
distinguishable higher than the bulk temperature; whereas with an interlayer crust, the interface temperature in the center was not elevated. The pattern of the temperature distribution discloses two symmetrically global cells of flow in the upper layer melt, which was also directly observed during the test via the transparent wall. Hot melt rose up from the center, drifted to both sides of the cooled wall, flowed energetically downwards along the cold wall and turned back along the bottom to the central and on this way it was gradually heated up again.

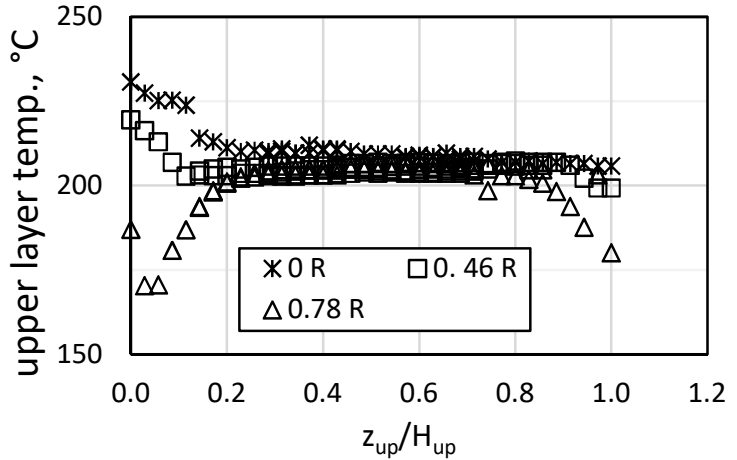

(a) SO1, $35 \mathrm{~mm}$ upper layer, $1.4 \mathrm{~kW}$

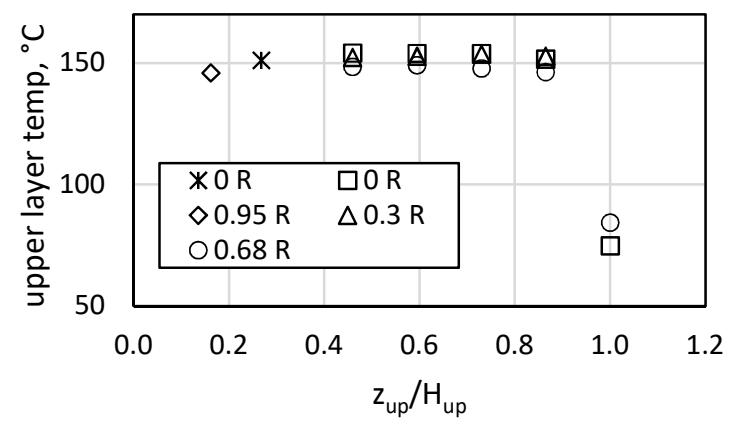

(c) SOTC, $37 \mathrm{~mm}$ upper layer, $4.3 \mathrm{~kW}$

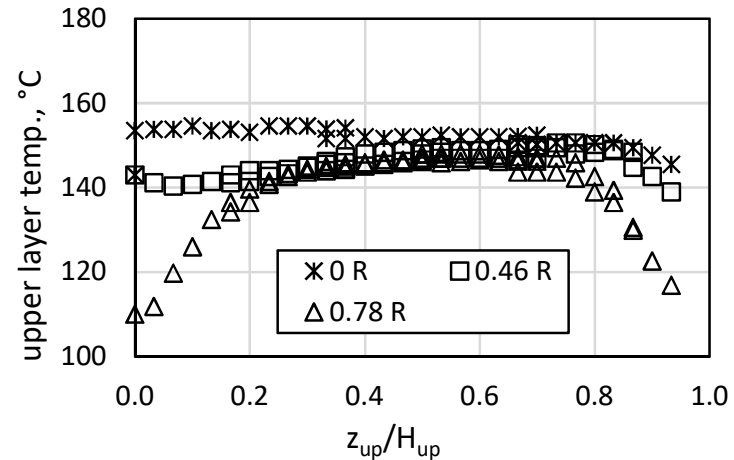

(b) SO1, $35 \mathrm{~mm}$ upper layer , $0.9 \mathrm{~kW}$

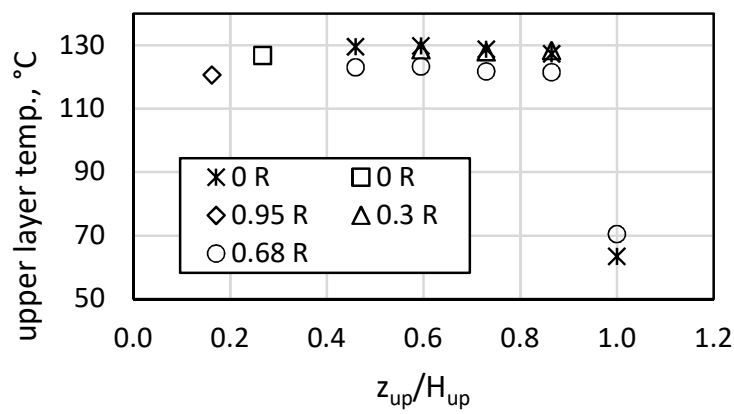

(d) SOTC, $37 \mathrm{~mm}$ upper layer, $3 \mathrm{~kW}$

Figure 5. Upper layer melt temperature in dimensionless upper layer position and radius. (a) and (b): SO1 test measured with mobile lance: (c) and (d) SOTC test measured with thermocouples in the melt and under the cooling lid.

During SOTC test, the upper layer melt rose up and descended in smaller wavelength and in slightly tilted angle to the cold wall. This pattern is similar as the Rayleigh-Bernard convection. The temperature measurements indicate a dominant uniform bulk temperature zone in axial and radial orientation, and properly very thin boundary layers, which cannot be exactly measured with thermocouples with $5 \mathrm{~mm}$ distance.

The different turbulent flow pattern in the upper layer and the consequently different melt temperatures between the two tests show the strong influence of the upper cooling condition on the heat transfer in the whole layer. With the additional upper surface rigid cooling, the upper layer temperature is low despite of the higher heat flux from the lower layer, and the upper layer temperature is not sensitive to the change of power and layer thickness. It creates a uniform interlayer crust and therefore a uniform bottom temperature. Rayleigh-Bernard convection is the dominant form and cooling of the sidewall has only side effect. Lacking of the surface rigid cooling leads to different turbulent flow pattern. The classic empirical heat transfer correlations for the estimation of the upper 
layer heat transfer, which are based on a uniform interface temperature of the whole layer, cannot be simply applied.

\subsection{Heat transfer on the sidewall}

- $\quad$ SO1 test

In the SO1 test, the sidewall heat flux corresponded to the melt temperature in the upper layer. Without effective upper surface cooling, the upper layer heat flux was very high comparing to the heat flux in the lower layer even at low power input. Figure 6 (a) to (c) show the heat flux distribution for different upper layer thicknesses in SO1 test. Increasing the upper layer thickness can effectively reduce the upper layer sidewall heat flux, which indicates that the heat transfer area on the vessel wall is the crucial factor to influence the heat flux focusing effect. In Figure 6 (d) a comparison of heat flux focusing ratio (HFF) is given, defined as the ratio of local heat flux to the average heat flux on the whole vessel wall, $\mathrm{q}_{\mathrm{w}} / \mathrm{q}_{\mathrm{w}}$ av. The highest HFF in SO1 test, which was over 6 , occurred during the thinnest upper layer $(35 \mathrm{~mm})$, whereas HFF reduced with the increase of the upper layer thickness.

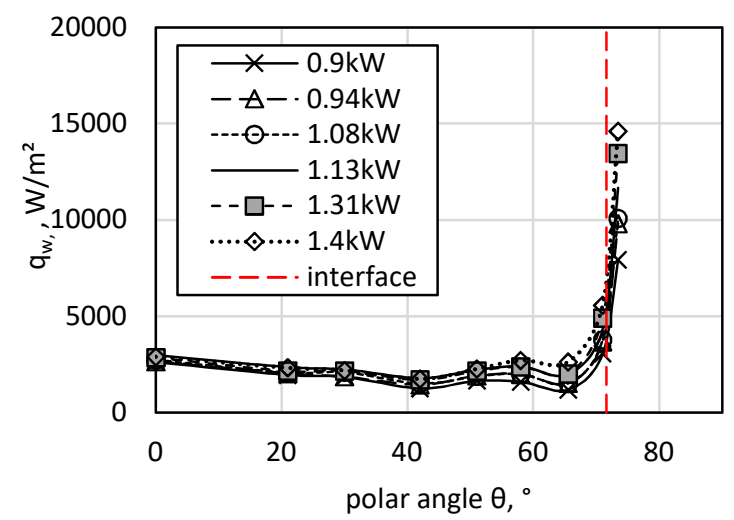

(a) SO1, with $35 \mathrm{~mm}$ upper layer

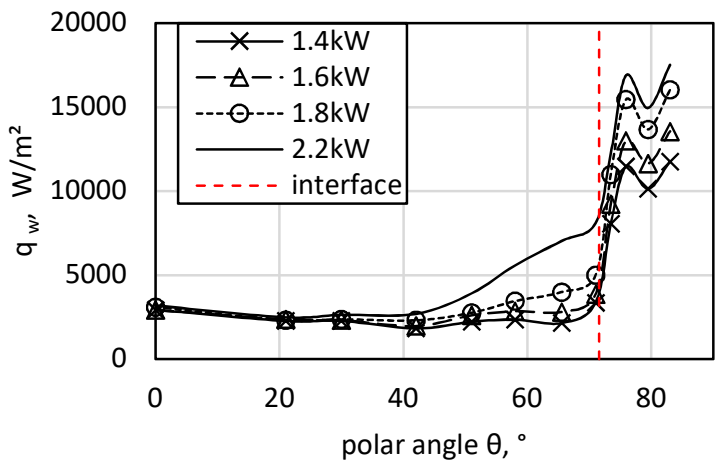

(c) SO1, with $110 \mathrm{~mm}$ upper layer

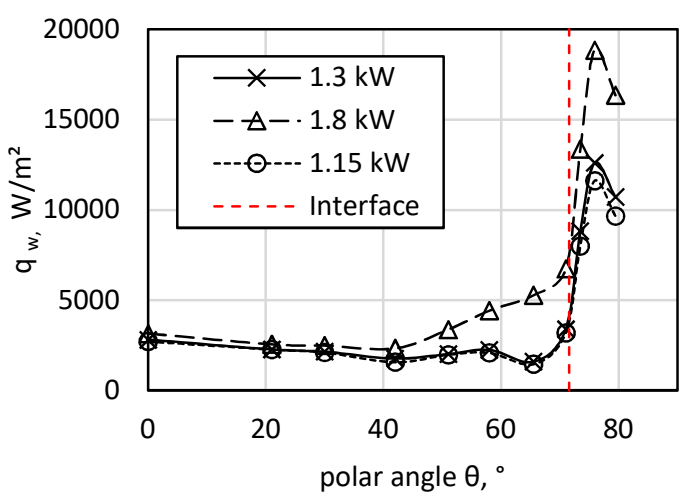

(b) SO1, with $75 \mathrm{~mm}$ upper layer

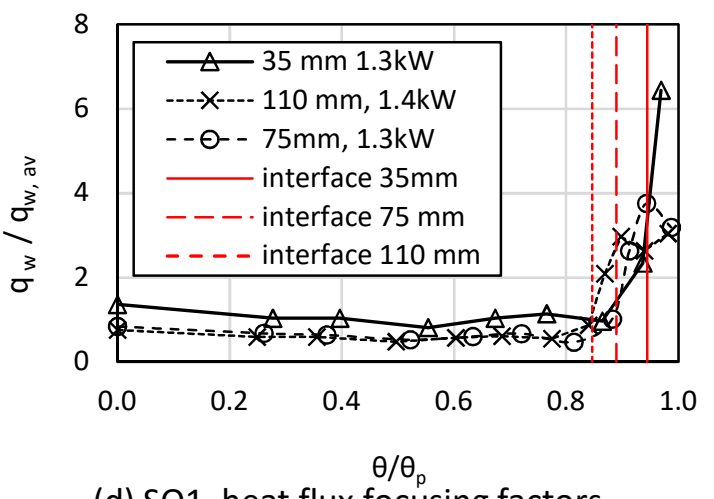

(d) SO1, heat flux focusing factors

Figure 6. Heat flux distribution in SO1 test. (a) with $35 \mathrm{~mm}$ upper layer, (b) with $75 \mathrm{~mm}$ upper layer,

(c) with $110 \mathrm{~mm}$ upper layer, (d) heat flux focusing ratio at different upper layer thicknesses.

\section{- $\quad$ SOTC test}

The heat flux focusing ratios in SOTC test are shown in Figure 7 (a) to (c). For all upper layer thicknesses, the HFF ratios in the upper layer were between $1-2$ times of the average, but generally not higher than the maximum heat flux in the lower layer. The highest local HFF ratio for each upper layer thickness was located in the lower layer near or at the two-layer interface and were mainly1.5 - 
3 times of the average heat flux. For the same power input, the maximum heat flux was the highest at the thinnest upper layer thickness.

SOTC test results show that the rigid upper surface cooling is the main driving factor to prevent the so-called heat flux focussing effect in the upper layer. The layer thickness plays only subordinated role for the heat flux response.

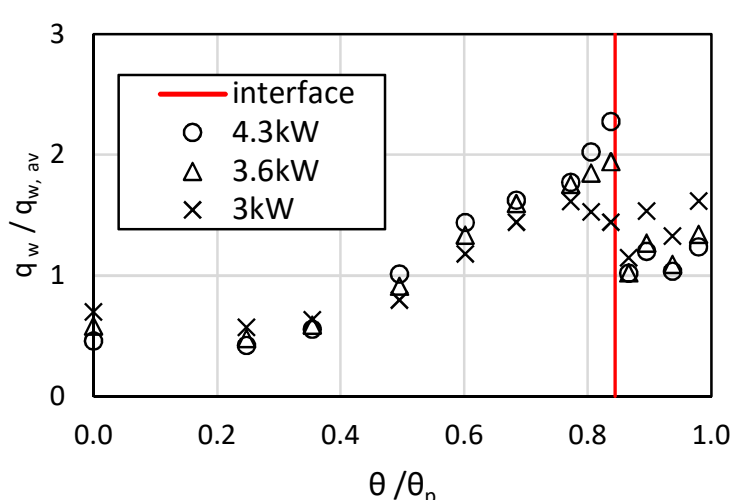

(a) SOTC, upper layer $112 \mathrm{~mm}$

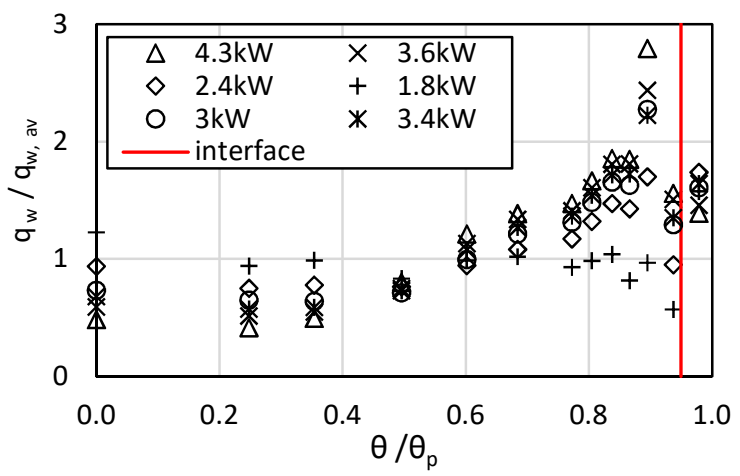

(c) SOTC, upper layer $37 \mathrm{~mm}$

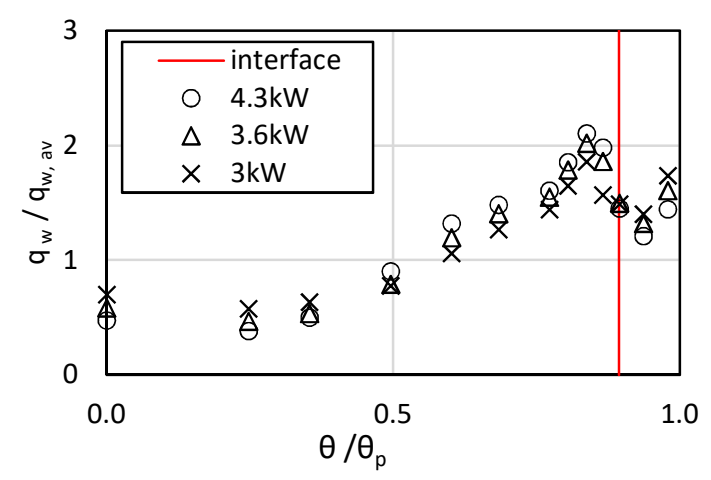

(b) SOTC, upper layer $77 \mathrm{~mm}$

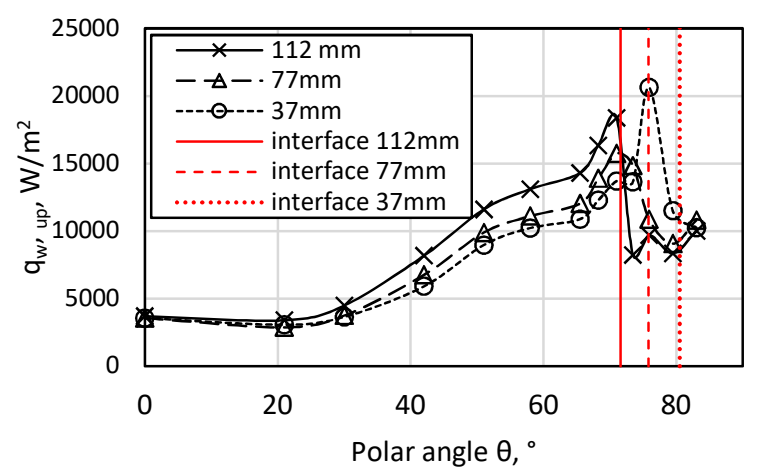

(d) SOTC, $4.3 \mathrm{~kW}$

Figure 7. Heat flux distribution in SOTC test. (a), (b) and (c): heat flux focusing ratios in SOTC test, (d) heat flux at $4.3 \mathrm{~kW}$ power input for different upper layer thicknesses.

The heat flux distribution in the upper layer is non-monotonic in both tests. In SO1 test a rapid rise of heat flux adjacent to the interface was observed, followed with non-monotonic course upwards. In SOTC test, the heat flux decreased strongly up from the interface, and then varied only slightly. A possible influence on the upper layer heat flux could be the heat conduction at the interlayer position and near the upper surface. Similar observation was made by the two-layer SIMECO test with high temperature Glycerol-Cerrobend [12]. At the adiabatic upper surface, the interlayer heat flux rose strongly at the interface and maintained high in the upper layer. Whereas with moderate or strong upper surface cooling, a heat flux drop at the interface was observed.

\subsection{General heat transfer parameters}

In Table 4 some important process parameters are given, including the status of the interlayer crust, the maximum melt temperature in the lower layer, the bulk temperature in the upper layer and the heat flux focusing ratio of the upper layer sidewall heat transfer. Besides these parameters, the check of thermal balance from the heat input and output of the whole pool and in each layer is also very important which examines the reliability of the experimental measurements and provides the frame 
for the simulation work of single boundary layers. The heat input values in the two tests are very reliable. It comes out to be difficult to estimate the radiative thermal loss through the transparent quartz plates and the heat transfer at the free upper surface of the upper layer in SO1 test. In SOTC test with the top water cooling, the heat transfer rate of the upper surface can be calculated according to the water-side parameters.

Some important thermal balance data are given in Table 5. The sum of the heat transfer rate through the cooled top and sidewall boundaries is firstly compared with the heat input. The thermal balance indicates an average thermal loss of $12 \%$ with the uncertainty of $7.7 \%$. In the following estimations of the thermal balance in each layer, the thermal loss is ignored since it is difficult to distribute it into each layer. For the thermal balance within the two layers, the heat flux ratios are given instead of the heat transfer rate ratios, because the heat transfer rate ratio in a $2 \mathrm{D}$-slice doesn't represent the relationship in a 3D reactor lower head. The top/sidewall average heat flux ratios in the lower layer and in the upper layer are 3.7 and 2.3 respectively. Both ratios show declining trends with increasing power. Finally, the heat flux at the sidewall boundary in SOTC test with top cooling condition is compared with the theoretical vessel wall with adiabatic top surface. The average is 0.27 , and with higher ratios at higher power inputs. Concerning the heat loss and the case with even higher power density, the sidewall/top surface heat rate in 3D geometry can be roughly estimated at least with 0.3 / 0.7 under the top surface cooling condition. The heat splitting ratio is however only applied to 2D geometry, since the upper surface cooling is over-emphasised, which is discussed in the following section related to the geometry effect. A ratio larger than $30 \%$ of heat transfer on the sidewall is expected in a 3D geometry.

Table 4.

Some important process parameters in the SO1 and SOTC tests.

\begin{tabular}{|c|c|c|c|c|c|c|c|c|c|c|c|}
\hline \multicolumn{6}{|c|}{ SO1 test } & \multicolumn{6}{|c|}{ SOTC test } \\
\hline $\begin{array}{l}\text { Upper } \\
\text { layer, } \\
\mathrm{mm}\end{array}$ & $\begin{array}{l}\text { Power } \\
\text { kW }\end{array}$ & $\begin{array}{l}\text { Inter- } \\
\text { layer } \\
\text { crust }^{1}\end{array}$ & $\begin{array}{l}T_{\text {max }, l o} \\
{ }^{\circ} \mathrm{C}\end{array}$ & $\begin{array}{l}\mathrm{T}_{\text {bulk,up }} \\
{ }^{\circ} \mathrm{C}\end{array}$ & $\begin{array}{l}q_{\text {w up, av }} \\
/ q_{\text {tot,av }}\end{array}$ & $\begin{array}{l}\text { Upper } \\
\text { layer, } \\
\mathrm{mm}\end{array}$ & $\begin{array}{l}\text { Power } \\
\text { kW }\end{array}$ & $\begin{array}{l}\text { Inter- } \\
\text { layer } \\
\text { crust }^{1}\end{array}$ & $\begin{array}{l}T_{\max , 10} \\
{ }^{\circ} \mathrm{C}\end{array}$ & $\begin{array}{l}\mathrm{T}_{\text {bulk, up }} \\
{ }^{\circ} \mathrm{C}\end{array}$ & $\begin{array}{l}q_{w}, \text { up, } \\
/ q_{w}, \\
\text { tot,av }\end{array}$ \\
\hline \multirow{6}{*}{35} & 1.13 & 1 & 232 & 186 & 5.7 & \multirow{6}{*}{37} & 3.6 & $4 / 5$ & 256 & 139 & 1.5 \\
\hline & 0.94 & 1 & 230 & 170 & 5.6 & & 3 & 1 & 248 & 128 & 1.7 \\
\hline & 1.1 & 1 & 231 & 172 & 5.6 & & 4.3 & $1 / 3$ & 265 & 151 & 1.4 \\
\hline & 1.3 & 1 & 235 & 201 & 6.4 & & 3.4 & 1 & 252 & 140 & 1.7 \\
\hline & 1.4 & 0 & 238 & 211 & 6.5 & & 2.4 & 1 & 241 & 112 & 1.8 \\
\hline & 0.9 & 1 & 229 & 153 & 5.1 & & 1.8 & 1 & 236 & 92 & 1.6 \\
\hline \multirow{4}{*}{75} & 1.3 & 1 & 238 & 163 & 3.2 & \multirow{3}{*}{77} & 4.23 & $1 / 4$ & 266 & 153 & 1.4 \\
\hline & 1.8 & 0 & 244 & 207 & 3.2 & & 3 & 1 & 257 & 144 & 1.6 \\
\hline & 1.15 & 1 & 232 & 153 & 3.1 & & 3.6 & $1 / 2$ & 249 & 131 & 1.5 \\
\hline & 1.6 & $1 / 4$ & 239 & 200 & 3.4 & \multirow{3}{*}{112} & 3 & 1 & 250 & 130 & 1.4 \\
\hline \multirow{4}{*}{110} & 2.2 & 0 & 251 & 206 & 2.6 & & 3.6 & 0.9 & 259 & 138 & 1.2 \\
\hline & 1.8 & $1 / 4$ & 240 & 195 & 2.8 & & 4.25 & $1 / 4$ & 268 & 152 & 1.1 \\
\hline & 1.4 & 1 & 234 & 163 & 2.7 & & & & & & \\
\hline & 1.6 & $1 / 3$ & 238 & 177 & 2.8 & & & & & & \\
\hline
\end{tabular}

${ }^{1}$ : portion of crust area at the interface: 1 : closed crust layer, 0 : no crust. 
Table 5 .

Some heat transfer ratios in SOTC test

\begin{tabular}{|c|c|c|c|c|c|c|c|c|c|c|c|c|c|}
\hline & \multicolumn{3}{|c|}{$112 \mathrm{~mm}$ upper layer } & \multicolumn{3}{|c|}{ 77mm upper layer } & \multicolumn{6}{|c|}{$37 \mathrm{~mm}$ upper layer } & average \\
\hline$Q_{\text {in }}, k W$ & 3.00 & 3.60 & 4.30 & 4.30 & 3.00 & 3.60 & 3.60 & 3.00 & 4.30 & 3.40 & 2.40 & 1.80 & \\
\hline$Q_{\text {out tot }} / Q_{\text {in }}{ }^{1}$ & 1.05 & 0.99 & 0.85 & 0.86 & 0.80 & 0.83 & 0.84 & 0.85 & 0.83 & 0.85 & 0.96 & 0.85 & 0.88 \\
\hline$q_{\text {int }} / q_{w}, 10^{2}$ & 4.92 & 3.73 & 2.67 & 2.99 & 3.43 & 3.18 & 3.23 & 3.83 & 2.77 & 3.63 & 4.99 & 4.72 & 3.7 \\
\hline$q_{\text {top }} / q_{w \text { up }}{ }^{3}$ & 2.99 & 2.82 & 2.09 & 1.96 & 1.91 & 1.88 & 2.09 & 2.23 & 1.88 & 2.06 & 2.69 & 2.83 & 2.3 \\
\hline $\begin{array}{l}q_{\text {wav }} / \\
q_{\text {w.top adiab }}{ }^{4}\end{array}$ & 0.27 & 0.31 & 0.33 & 0.31 & 0.27 & 0.25 & 0.28 & 0.25 & 0.30 & 0.26 & 0.23 & 0.21 & 0.27 \\
\hline
\end{tabular}

${ }^{1}$ : Ratio of the total heat transfer rate of top surface and external boundary to the heat input

2 : Lower layer balance: ratio of heat flux through the two-layer interface to the heat flux through the sidewall in the lower layer.

3 : Upper layer balance: ratio of heat flux at the upper surface to the heat flux to the heat flux at the upper layer sidewall.

${ }^{4}$ : Ratio of the average sidewall heat flux in SOTC test with top cooling to the theoretical sidewall heat flux with adiabatic top surface boundary.

\section{Discussions}

\subsection{Nu Ra correlations of the upper layer}

Concerning a light metallic layer with no internal heat source, heated from the ceramic layer below, and cooled from the top and the side, there is no simple correlation describing the convection in this case. As LIVE2D SO1 and SOTC test results have shown, the buoyancy driven convection pattern can be completely different depending on the strength of the cooling at the top. With a strong cooling at the top, the convection is similar to a Rayleigh-Bernd convection with alternative uprising and descending flows, whereas without this strong top cooling and influenced by the strong side cooling, the convection is a coupled Buoyancy Marangoni convection, where the flow is horizontal at the upper and bottom boundaries [18].

This case becomes more complex when a non-continuous ceramic crust at the interlayer boundary leads to different interlayer temperature in radial direction. The existing literatures describe majorly the case with strong top cooling and with uniform bottom boundary temperature [19].

In Table 6 the well-known $\mathrm{Nu} \sim$ Ra correlations at the vertical sidewall and at the horizontal upper and bottom boundaries and the empirical correlation from LIVE2D results are listed. The general form of the correlation can be described as

$$
N u=C R a^{m} \operatorname{Pr}^{n}
$$

In the field of reactor research application, the exponent " $m$ " of $\mathrm{Ra}$ in $\mathrm{Eq}(1)$ is generally given as $1 / 4$ for laminar flow where $\mathrm{Ra} \leq 10^{9}$, and it increases to $1 / 3$ for the turbulent flow where $\mathrm{Ra}>10^{9}$ [20]. Theofanous [2] specialized the Churchill\&Chu turbulent correlation [20] of the Globe \& Dropkin correlation [21] and has deleted the Pr part in his formulations. 
Table 6.

Empirical correlations for the light metallic layer vertical boundary and horizontal boundaries.

\begin{tabular}{|c|c|c|c|}
\hline Authors /Experiment & $\mathrm{Nu} \sim \mathrm{Ra}$ corrleration & Ra & $\operatorname{Pr}$ \\
\hline \multicolumn{4}{|c|}{ Vertical sidewall } \\
\hline Churchill \& Chu & $N u=0.68+\frac{0.67 R a^{\frac{1}{4}}}{\left[1+\left(\frac{0.492}{P r}\right)^{\frac{9}{16}}\right]^{\frac{4}{9}}}$ & $\leq 10^{9}$ & All $\mathrm{Pr}$ \\
\hline Churchill \& Chu & $N u=\left\{0.825+\frac{0.387 R a^{\frac{1}{6}}}{\left[1+\left(\frac{0.492}{P r}\right)^{9 / 16)}\right]^{\frac{8}{27}}}\right\}$ & $<10^{12}$ & All $\mathrm{Pr}$ \\
\hline Theofanous & $N u=0.076 R a^{1 / 3}$ & $<10^{12}$ & $\sim 0.13$ \\
\hline LIVE2D experiment & $N u=0.044 R a^{1 / 3}$ & $>10^{9}$ & 100 \\
\hline & $N u=0.2 R a^{1 / 4}$ & $\leq 10^{9}$ & \\
\hline \multicolumn{4}{|c|}{ Horizontal bottom and upper surface } \\
\hline Globe \& Dropkin & $N u=0.069 R a^{1 / 3} \mathrm{Pr}^{0.074}$ & $3 \cdot 10^{5}-7 \cdot 10^{9}$ & $0.02-8750$ \\
\hline Theofanous \& Liu & $\begin{array}{c}N u=0.059 R a^{1 / 3}(1) \\
N u=0.1 R a^{0.31}(2)\end{array}$ & $\sim 10^{10}$ & $\sim 0.13$ \\
\hline LIVE2D experiment & $N u=0.069 R^{1 / 3} \operatorname{Pr}^{0.074}$ & $10^{7}-5 \cdot 10^{9}$ & 100 \\
\hline
\end{tabular}

The LIVE2D results on the heat transfer at the vertical sidewall and the two horizontal boundaries are compared with these correlations, and are illustrated in Figure 8. In case of the heat transfer at the cooled sidewall, LIVE2D results are only about $1 / 3$ of the Churchill \& Chu correlation and are also lower than the Theofanous correlation. The difference lays properly in the constant " $\mathrm{C}$ " in Eq. (1), whereas power law " $\mathrm{m}$ " with the values of $1 / 4$ and $1 / 3$ for laminar and turbulent flow are applicable. The constant " $\mathrm{C}$ " in the LIVE2D correlations are therefore also given in Table 6, and are shown in the left diagram in Figure 8. Keeping the power law in Eq. (1) at 1/3, the decrease of constant $\mathrm{C}$ in eq.(1) is about $58 \%$. Concerning the heat transfer at horizontal boundaries, the LIVE2D results agree quite well with the Globe \& Dropkin correlation, and are higher than the Theofanous correlations. This decrease can come from the difference in the Pr. Hartlep [22] describes the same trends by increasing Pr, that e.g. the "C" constant decreases about 55\% from Pr of 0.7 to 30 at Ra number of $10^{7}$.

Numerous studies exclusively on the Rayleigh-Bernard convection indicate that Pr number has influence on the exponent " $m$ " and " $n$ " in Eq. (1). Grossmann [23] summarized the early studies that there is a trend of the exponent " $\mathrm{m}$ " as a function of Pr. For the case of water with $\operatorname{Pr} \sim 5-7$, the exponent " $m$ " is $2 / 7$ when $R a<10^{9}$, and $1 / 3$ when $R a>10^{9}$. For $\operatorname{Pr}=0.7-1$, m approaches to 0.282 $(\sim 2 / 7)$, and for $\operatorname{Pr} \sim 0.025, \mathrm{~m}$ reduces to $1 / 4$. Younis even stated that at very large Pr numbers, the $\mathrm{Nu}$ number is independent of $\operatorname{Pr}[24]$. The significance of the Pr number influence is depending on the turbulent regime whether it is dominant by kinetic or thermal boundaries, or by the kinetic and thermal 
bulks. Hartlep comments that the dynamics of fluid with $\mathrm{Ra}>10^{7}$ is governed primarily by the properties of the thermal boundary layers. Theoretically, the thermal boundary layer $\delta_{\theta}$ and the kinetic boundary layer $\delta_{v}$ can be calculated as [25]:

$$
\delta_{\theta}=\frac{L}{2 N u}(a) ; \delta_{v}=\frac{L}{4 \sqrt{R e}}(b)
$$

Grossmann has defined four regimes according to different dominant factors and gave the values of exponent " $m$ " and " $n$ " in Eq. (1) for each regime. Different as in LIVE2D test simulant, for a metallic layer with low Pr number, the thermal boundary layer is larger than the kinetic boundary layer and properly dominates the whole regime, at moderate Ra number $\left(<10^{10}\right)$, regime I with $N u=$ $0.27 \mathrm{Ra}^{1 / 4} \mathrm{Pr}^{1 / 8}$ is recommended [23].
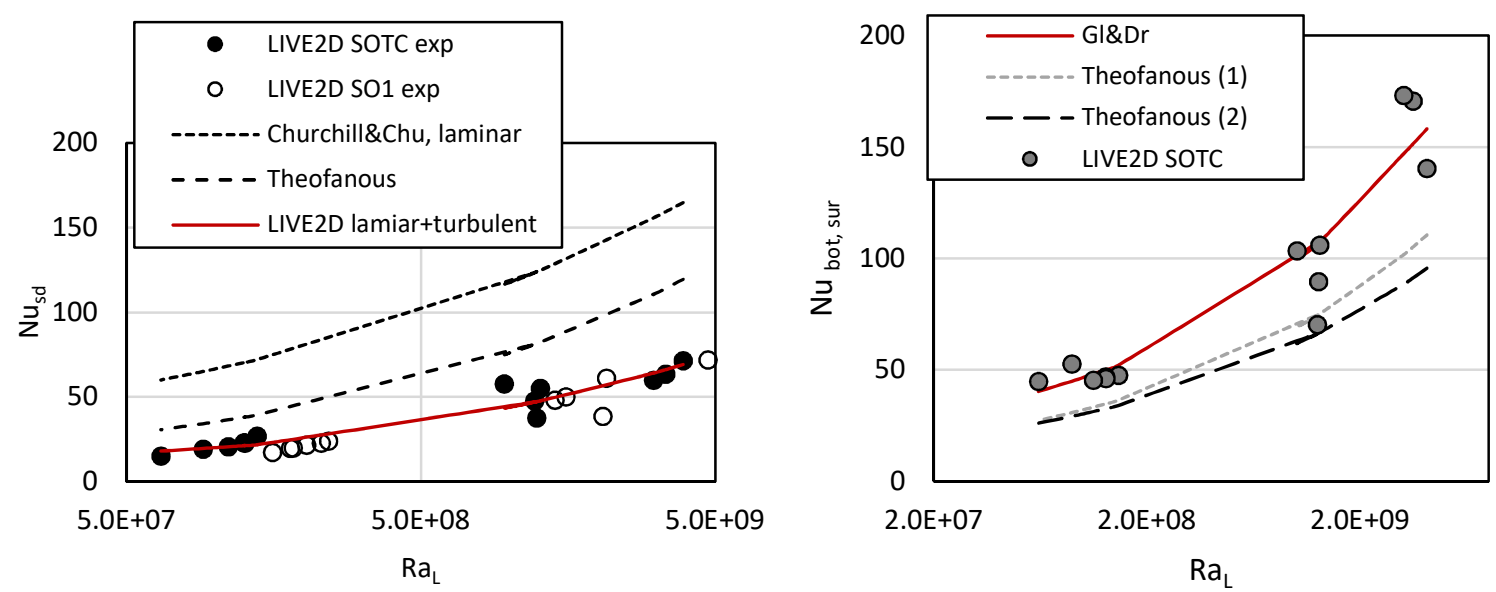

Figure 8. Empirical heat transfer correlations for the upper metallic layer: left: at vertical wall, right: at the upper surface and bottom boundary.

Concerning the wavelength of the uprising and descending periodic flows, its mean wavelength seems to be similar for fluids with $\operatorname{Pr}<0.7$ and with $\operatorname{Pr}>20$, which is about 4 - 5 times of the layer thickness, but has peek values for the fluid with moderate Pr numbers, e.g. water [26].

It is also worth noting that when the exponent " $m$ " in eq. (1) is $1 / 3$, the heat transfer coefficient " $h$ " is independent on the height of the layer " $L$ ". The relationship can be shown in eq. (2), applying the Ra in eq. (1), $L$ is vanished by balance $L^{3}$ in Ra.

$$
h=\frac{N u \lambda}{L}=\frac{C R a^{\frac{1}{3}} \lambda}{L}=\frac{C \lambda}{L}\left(9.8^{\cdot} \beta \Delta T L^{3} /(\alpha \nu)\right)^{1 / 3}=9.8^{\cdot} \cdot C \lambda(\beta \Delta T /(\alpha \nu))^{1 / 3}
$$

\subsection{Effect of geometry}

A general question always arises on the applicability of 2D test results on a 3D hemispherical lower head. A reasonable suppose is that the general characteristics of natural convection on a certain heat transfer boundary represented as $\mathrm{Nu}$ number can be applied independently on the geometry of its cavity, given that this area is large enough in comparison to the layer thickness so that the convection flow pattern is not disturbed by its neighbour boundaries. Other parameters, including area-averaged heat flux and local heat flux at each boundary, and the up/down heat rate split, cannot be applied directly to $3 \mathrm{D}$ geometry, since the determination of these process parameters in an experiment is dependent on the temperature difference between the bulk melt and the individual boundary 
temperatures, as shown in Eq. (3). Both the maximum value and the distribution of the bulk temperature in a melt layer adjust themselves to the heat balance among all boundary layers, and is variable depending on the individual boundary temperature and its heat transfer area.

$$
q_{i}=\frac{N u_{i} \lambda}{L_{i}} \Delta T_{i,} \text { : a certain boundary }
$$

If the temperature differences at all or some boundaries are uniform, such as in the case of the melting temperature of steel in the upper metallic layer upper surface and sidewall, or a crust bounds all the boundaries of a ceramic pool, the ratios of heat flux between these boundaries reflect directly the ratios of $\mathrm{Nu}$ for the same geometry. Even under same boundary temperature, the bulk temperature in 2D and in 3D is different. A comparison of the Area Aspect Ratio in Eq. (4) between 2D semi-circular and $3 \mathrm{D}$ cylinder reveals the influence of the geometry.

The area aspect ratio is defined here as the ratio of the top surface area to the sidewall area $\Gamma$ with $\Gamma=\frac{A_{t o p, b o t}}{A_{s d}}$. For the same layer height $\mathrm{L}$ in $2 \mathrm{D}$ and $3 \mathrm{D}$, and a certain width $\mathrm{D}$ of the $2 \mathrm{D}$ slice, the area aspect ratios of a $3 \mathrm{D}$ cylinder and a $2 \mathrm{D}$ semi-circular slice are

$$
\Gamma_{3 D}=\frac{\Pi R^{2}}{2 \Pi R L}=\frac{R}{2 L} ; \Gamma_{2 D}=\frac{2 R D}{2 L D}=\frac{R}{L}
$$

Eq. (4) indicates that upper/bottom surface in a $2 \mathrm{D}$ geometry is proportionally twice as in a 3D geometry. Therefore, the heat transfer ability at the horizontal surface in $2 \mathrm{D}$ geometry can be twice as in 3D. In other words, the heat transfer rates at horizontal surfaces in $2 \mathrm{D}$ is over-emphasised. For an adiabatic upper surface, the heating at the bottom is over-emphasised in $2 \mathrm{D}$ and it results in higher bulk temperatures than in a 3D geometry. In the opposite case with a strong rigid cooling on the upper surface, the upper surface cooling is over-emphasised so that its bulk temperature will be lower than in a 3D cavity. The concrete determination of the bulk temperature change is based on the $\mathrm{Nu}$ formulation (Eq. (1)) on each boundary, and on the boundary temperatures. A general interpretation of the 2D to 3D result transition have no significance. Furthermore, if the exponent " $m$ " is $1 / 3$ for all boundaries, the bulk temperature is based only on the different " $C$ " in Eq. (1).

Similar effects were also observed for a homogenous ceramic pool, where the Area Aspect ratio in 2D is larger than in 3D in general. An additional effect comes from the area proportion difference along the curved vessel wall between the 2D circular to 3D hemispherical geometry. The geometrical influence on the heat transfer in a volumetric heated pool is reported in [27] by comparing LIVE3D and LIVE3D results.

\subsection{Response of heat transfer in the lower layer}

The response of heat transfer in the lower layer is similar as a homogenous one-layer oxide pool with different upper boundary conditions. Generally, the heat flux at the vessel wall increases and the crust thickness decreases as power increases in the lower layer. The heating power in SOTC test was about twice as in SO1 test, a clear heat flux increase in the upper region of the lower layer is observed by comparing Figure 6 (a), (b), (c) with Figure 7 (d). The experiment has also shown that the profile of the heat flux is different depending on whether the interlayer crust exists. With an interlayer crust, the upper boundary and the lower boundary in the lower layer is isothermal and thus the up/down heat transfer ratio is constant. If the interlayer crust is disappeared, an indication that the upper boundary temperature is higher than the temperature at the interface of crust/wall, the heat transport to the upper layer is correspondingly reduced based on the less temperature difference between bulk and upper 
boundary. The reduced upper heat transfer rate is then compensated by higher thermal load on the vessel wall, and especially at the upper region of it. This trend is shown for example in Figure 6 (b), at $1.8 \mathrm{~kW}$, and Figure 7 (c) at $2.2 \mathrm{~kW}$. At these power stages there was no interlayer crust. The heat flux distributions in an oxide pool with different upper cooling conditions are described extensively in [13]."

\section{Conclusion}

Two test series on melt stratification tests with simulant materials were performed in LIVE2D facility at KIT. Natural separation of the simulants and the possibility of crust formation of the lower layer simulant have been realized. The heat transfer coupling between the two layers were studied in global scale and the impact on the interlayer crust was analysed. The two test series with different upper cooling conditions demonstrated the significant influence of the upper cooling on the natural convection in the upper layer, and its positive effect on the heat flux focusing effect on the sidewall.

SO1 test showed that in case of a poor upper surface cooling the interlayer crust thickness is not uniform in radial direction due to the different temperature at the upper layer bottom. In some circumstances, only the outer ring of the interface was separated with a crust layer, and the two liquid layers have direct contact in the center area. With a strong surface cooling, another flow pattern occurs which enables uniform bulk temperature and bottom temperature. The interlayer crust acts as a barrier preventing the direct temperature coupling between the layers.

The strong upper surface cooling can effectively supress the bulk temperature in the upper layer and maintain the heat flux focusing effect in a low level. The increasing upper layer thickness is also not essential to minimize the sidewall heat flux. A limited upper surface cooling leads to a sharp reaction of the heat flux on the sidewall, and the heat flux focusing factor can be as higher as 5 to 6 times to the average one for a thin upper layer.

Above temperature and crust behaviour are the result of natural convection in the upper layer melt, which is strongly influenced by the heating and cooling conditions on all boundaries. Under the condition of strong heating at the bottom and rigid cooling at the upper surface and at sidewall, the convection is similar to Rayleigh-Bernard convection. The flow moves mainly alternatively in up and down directions with small wavelength. The heat transfer at the upper surface is the main source of cooling and the sidewall cooling acts only as side effect. With absence of the cooling source at the upper surface, the sidewall cooling takes the main burden of heat transfer, and the flow circulates globally from the hot center to the cold wall region.

This study also demonstrates that the heat flux focusing reduces when the interlayer boundary is crustfree. A rise of bulk temperature in the lower layer corresponding to high decay power works two folds: reduction of the upward heat transfer since the temperature difference between the lower layer bulk and the interface is smaller; and increase of the heat flux on its own wall areas.

Finally, heat transfer correlations of former studies are compared with LIVE tests. The LIVE test results agree very well with Globe \& Dropkin correlation on the upper surface, and is considerably lower than the Churchill\& Chu and Theofanous correlations for the vertical wall. Therefore a new set of correlations based on the LIVE tests are given. The influence of Pr number on the correlation and the influence of geometry on some of the heat transfer parameters are discussed. The unique results from this study provide a global view on the two-layer heat transfer problematics. To obtain reliable 
heat transfer correlations in a metallic layer, this study should be validated with further large-scale tests using low Pr simulant for the upper melt layer. 